\title{
GERENCIAMENTO DO CAPITAL HUMANO \\ EM BIBLIOTECAS OU CENTROS DE INFORMAÇÃO: DESAFIO IMPOSTO PELA SOCIEDADE DO CONHECIMENTO*
}

\section{HUMAN CAPITAL MANAGEMENT IN LIBRARIES OR INFORMATION CENTERS: CHALLENGE FROM THE KNOWLEDGE SOCIETY}

\author{
Angela Maria OLIVEIRA * * \\ amolivei@uepg.br \\ Antonio Costa GOMES FILHO** \\ acgomes@uepg.br \\ Astrid HONESKO** \\ ahonesko@uepg.br \\ Edmeire C. PEREIRA*** \\ estela@cieg.ufpr.br
}

RESUMO

Este artigo procura discutir aspectos relacionados ao capital humano atuante em bibliotecas ou centros de informação, analisando as habilidades gerais e especificas necessárias aos profissionais dos setores de Aquisição e Referência (inicio e flm do processo informacional). Propõe uma reflexão sobre o conceito de organizações do tipo "learning organizations". Conclui que a grande mudança de paradigmas da atualidade está no modelo mental de seus gestores, dentro da ótica de líderes educadores. Eis um grande, senão, o maior de todos os desafios impostos pela sociedade do conhecimento.

Palavras-chave: Capital Intelectual; Capital Humano; Conhecimento Tácito; Learning Organizations (conceito); Gestão de Pessoas; Gerentes e Lideres; Sociedade do Conhecimento; Aquisição; Referência.

\section{ABSTRACT}

This paper discusses aspects of the human capital working in libraries or information centers, analyzing the general and specific skills of the modern information professionals in the Acquisition and Reference Services (beginning and end of the informational process). The

\footnotetext{
(*) Trabalho realizado a partir da disciplina de Gerência de Recursos Informacionais, ministrada pela Profa. Dra. Rose M. J. Longo, nos meses de maio e junho de 2000.

(“) Mestrandos do Programa de Pós-Graduação em Biblioteconomia e Ciência da Infonnação - Convênio CAPES MINTER/PUC-Campinas e UFPR. Oriundos da Universidade Estadual de Ponta Grossa (PR).

(*.*) Mestranda do Programa de Pós-Graduação em Biblioteconomia e Ciência da Informação - Convênio CAPES MINTER/PUC-Campinas e UFPR. Professora da UFPR.
} 


\begin{abstract}
learning organization concept is focalized. It concludes that the greatest change is in the mental models of managers, from the point of view of educational leaders this is, certainly, the biggest challenge that is imposed on us by knowledge society.
\end{abstract}

Key-words: Intellectual Capital; Human Capital; Tacit Knowledge; Learning Organizations; People management; Managers and leaders; Knowledge Society; Acquisition; Reference Service.

\section{INTRODUÇÄO}

A estrutura da sociedade moderna baseia-se no conhecimento e no capital humano. Seu produto é fruto da criatividade, imaginação e aptidão do ser humano. $O$ poder da mente humana em adaptar-se ao meio que o cerca faz com que o desafio de defrontar-se com as mutações sociais, culturais e econômicas torne-se conseqüência de sua própria evolução.

Ao longo de toda a história as empresas sempre conviveram com a mudança, porém, nessa nova era, o que predomina é o conhecimento, o maior capital do futuro.

As organizações serão flexíveis, constituídas de equipes multifuncionais com redes de comunicação intensivas para irradiar o conhecimento.

O que mudará nas pessoas que comandarão estas empresas, quais serão as exigências, o que mudará nas pessoas que serão a sustentação do novo modelo de administração? Sem dúvida, o novo operário precisará ser produtivo, criativo, flexível e capaz de explorar o conhecimento como principal insumo para adaptar-se às contínuas e incessantes mudanças num processo de equilíbrio da sociedade, devendo, portanto, ser repensada a formação cultural e profissional, enfocando as novas perspectivas de qualificação profissional.

"Este novo conceito de trabalho muda o perfil do profissional que chamávamos 'mão-de-obra' e exige um novo perfil de profissionais que passaremos a denominar de 'mente-de-obra" (SILVA,1998, p. 49).

O investimento em educação se fará necessário nos processos de treinamento, na preparação para a competição na era da globalização. Hoje, os empregos não têm mais o caráter de vitalícios, mas, sim, oportunidades temporárias de adquirir-se experiência, conhecimento e competência, e o futuro prevê que as pessoas raramente iniciarão um emprego em uma empresa e terminarão sua carreira na mesma. A ênfase na produtividade, na criação de novos produtos, na qualidade tem avançado de maneira significativa, mas a gestão das pessoas ainda tem mantido a visão de paradigmas do passado.

Toda mudança começa pela mudança de si mesmo, mudanças essas que deverão ter início com a ênfase na área de treinamento e desenvolvimento. As pessoas devem buscar uma auto-reciclagem e não apenas fazer o que diz o manual. Nessa nova interpretação da realidade, cada profissional venderá seu produto ou serviço diariamente. Pessoas capacitadas para uma só tarefa, acomodadas, não terão lugar nos novos espaços de trabalho que estão surgindo.

Uma grande habilidade exigida para o profissional do futuro é aprender a interagir com o novo.

Para entender o contexto da sociedade do conhecimento é necessário dominar os conceitos básicos de Learning Organization e Capital Intelectual.

Learning Organization é o nome dado às organizações que aprendem, ou seja, àquelas organizações capazes de utilizar o capital intelectual eficazmente. "O significado básico de uma 'organização que aprende' - uma organização que está continuamente expandindo sua capacidade de criar seu futuro" (SENGE 1998, p. 47,).

$\mathrm{Na}$ sociedade do conhecimento qualquer organização pode tornar-se uma learning organization, desde que consiga integrar os recursos disponíveis e principalmente utilizar o conhecimento de seus colaboradores.

Para STEWART (1998, p. 13): "capital intelectual constitui a matéria intelectual - conhecimento, informação, propriedade intelectual, experiência - que pode ser utilizada para gerar riqueza". O autor subdivide o capital intelectual em capital humano, capital estrutural e capital do cliente.

Nossa proposta é analisar aspectos relacionados ao capital humano que atua em bibliotecas ou centros de informação na era do conhecimento, analisando as habilidades gerais necessárias ao profissional da informação e habilidades específicas exigidas àqueles que atuam nos setores de Aquisição e Referência, cobrindo o início e o fim do processo do ciclo informacional, pois em função das novas tecnologias, os modelos de estruturas organizacionais estão mudando radicalmente e, sem dúvida, nesse novo contexto, as habilidades pessoais necessárias também sofrem alterações. 
Abordaremos, ainda, o problema do gerenciamento desse capital humano necessário em bibliotecas ou centros de informação, o que fatalmente exigirá um novo modelo mental a ser adotado pelos seus dirigentes, que devem passar a possuir um novo perfil, o perfil de líder. Tal líder deverá ser antes de tudo um educador e as funções de treinamento e desenvolvimento deverão evoluir para aprendizado e educação.

Não pretendemos esgotar o assunto, mas alertar os leitores para a realidade que aí está, presente em todas as organizações. As bibliotecas ou centros de informação deverão ser vistas por seus dirigentes como organizações, ou learning organizations. Esse novo paradigma traz-nos desafios de gerenciamento, não só dos recursos materiais, tecnológicos e financeiros, mas, principalmente, do capital humano necessário para inserir as bibliotecas ou centros de informação na era do conhecimento.

\section{O BIBLIOTECÁRIO VISTO COMO PROFISSIONAL DE INFORMAÇĀO}

O século XXI traz aos bibliotecários uma oportunidade nunca antes vista: a oportunidade de firmar-se como profissional da informação; mas somente sobreviverá aquele profissional capaz de desenvolver as novas habilidades requeridas. É tempo do bibliotecário mudar totalmente seu perfl profissional, pois com o surgimento das novas tecnologias, a sociedade passou a exigir um novo profissional, que esteja apto a filtrar de forma eficaz e criativa as informações disponíveis nos sistemas informatizados, assim podendo acrescentar valor aos seus produtos e serviços.

LANCASTER concorda com isso, ao afirmar: "que as inovações tecnológicas e outras mudanças que estão ocorrendo no mundo tanto podem ser vistas como uma ameaça à biblioteca, ou como uma oportunidade rara para a Biblioteconomia tornar-se mais valiosa para a sociedade do que tem sido até agora" $(1994$, p. 8).

A cada dia que passa aumenta o volume de informações disponíveis no mundo e novas tecnologias aparecem no mercado como uma forma de proporcionar maior rapidez e eficiência no tratamento e recuperação da informação. Surgem novas atitudes que fogem totalmente àquelas efetuadas tradicionalmente, sendo essencial a mudança de perfil do bibliotecário, pois profissionais de outras áreas estão ocupando o setor de informação, e continuarão ocupando, caso os bibliotecários não desenvolvam as competências exigidas pelos novos tempos.
Novas ocupações estão sendo criadas, novas oportunidades se abrem, novas habilidades estão sendo demandadas, surgindo, assim, uma diversidade de carreiras relacionadas com informação. Todos os profissionais hoje estão sendo entendidos como profissionais da infonnação, pois necessariamente precisam manipular informação para o desempenho de seus papéis econômicos, politicos e sociais, como exigência natural da ordem dominante (MARENGO 1996, p.114).

O cenário da globalização já foi estabelecido e o mercado de trabalho começou a exigir que os profissionais da informação sejam mais versáteis, flexíveis, tenham visão gerencial e o bibliotecário precisa de reciclagem profissional para adequar-se às novas demandas.

A partir dessas exigências, não tem mais como o bibliotecário basear-se apenas nos moldes tradicionais para organizar a informação, ele precisa ir além, dominar a informática para utilizá-la como principal ferramenta de tratamento, recuperação e disseminação da informação. Entretanto, o bibliotecário precisa estar consciente de que novas tecnologias não vão apenas transformar o que era realizado manualmente em algo um pouco mais rápido. As tecnologias de informação devem ser consideradas como ferramentas básicas de trabalho, uma vez que o processamento, o gerenciamento, recuperação e disseminação da informação tornam-se mais eficientes e eficazes.

Para PENNIMAN (1993) citado em LANCASTER: "Precisamos planejar uma mudança na nossa orientação, de guardiães dos livros para guias através do universo do conhecimento.(...) A habilidade dos bibliotecários de serem criativos, de se moverem para fora da biblioteca, e para dentro de papéis mais amplos da informação, nos dará a medida do bibliotecário do futuro" (1994, p.10).

Verifica-se que o bibliotecário precisará mudar radicalmente seu posicionamento, de gerenciador de coleções para disseminador, refinador da informação.

Queremos que o profissional seja cada vez menos um monitor na organização de documentos. Queremos que ele seja um motivador do uso da informação. Que seja cada vez menos um cumpridor de tarefas rotineiras e cada vez mais um sintetizador ágil de informação; cada vez menos um administrador de coleções e cada vez mais um administrador de produtos e serviços de informação; menos um punidor de usuário e mais um promotor do cliente. Que não seja mais um centralizador de documentos, mas um jogador de equipe no processo de busca de informação; que não seja dependente do acervo, mas um entusiasta do acesso; não seja mais um obscuro num canto de quatro paredes, mas um empreendedor $e$ amante da 
visibilidade; não mais um intermediário passivo, mas um adicionador de valor à informação (MARCHIORI, 1996, p.31).

Percebe-se no discurso da autora a expressão "um jogador de equipe", tal exigência é típica da sociedade do conhecimento, saber trabalhar em equipe.

$\mathrm{Na}$ sociedade do conhecimento, mais do que um intermediador entre a informação e o usuário, o bibliotecário será um refinador de informação, assim contribuindo para a redução do tempo do usuário na recuperação da mesma, pois a mais utilizada tecnologia - Internet - possibilita o acesso a bilhões de informações, e o especialista da informação conhece os melhores caminhos para obter maior eficácia na busca.

Ao abordar uma discussão sobre o Moderno Profissional da Informação (MIP), MASON (1990), citado por GUIMARÃES, caracteriza esse profissional como "aquele que é capaz de fornecer a informação certa, da fonte certa, ao cliente certo, no momento certo, da forma certa e a um custo que justifique seu uso." (1998 p.21) Afirma, ainda, o autor, que o grupo dos profissionais da informação se integra por: administradores, arquivistas, analistas de sistemas, contadores, bibliotecários e museólogos, cada qual desempenhando o seu papel no grupo.

GUIMARÃES (1998, p.21) segue dizendo que o profissional da informação deve ser como no acróstico de PONJUÁN DANTE (1995): "Profundo, Rápido, Organizado, Flexível, Investigador, Simples, Sensato, Inovador, Orientado para o cliente, Natural, Ativo Laborioso".

Algumas atitudes e características podem ser indicadas como determinantes para o novo profissional da informação para esse tempo de mudanças, segundo WORMELL (1999) e LUCAS (1996), são elas:

- possuir habilidade para identificar e resolver problemas;

- facilitar o uso da informação;

- oferecer produtos não padronizados;

- oferecer esclarecimentos sobre o uso da informação;

- realizar treinamento e educação de usuários;

- oferecer excelente gerenciamento dos recursos informacionais;

- navegar entre sistemas de conhecimento e fontes de informação;

- oferecer serviços de tradução;

- realizar consultorias; e

- criar e inovar a partir de conhecimento e práticas adquiridas.
Entretanto, "o profissional da informação deve buscar a sua identidade no novo mercado, sem perder de vista a sua característica mais intrínseca de responsável pelo ciclo documentário e informacional. Deve apossarse de novos perfis, novas descrições de emprego, que sejam baseados nesta sua característica única". (TARAPANOFF, 1997, p. 35).

Somente depois da mudança de postura do profissional da informação poderemos vê-lo como ativo precioso de sua organização, pois a sociedade do conhecimento requer um comportamento profissional mais exigente do que a sociedade industrial do século passado.

\section{O RESPONSÁVEL PELA AQUISIÇÃO}

Em um ambiente de bibliotecas ou centros de informação tudo inicia-se com a seleção da melhor fonte de informação a ser adquirida. Nesse aspecto é necessário por parte dos dirigentes a definição de uma política de aquisição.

A primeira pergunta a ser feita pelos responsáveis pela aquisição é: o que deve ser comprado? Tal resposta deverá partir do profissional ou comissão responsável pela seleção e aquisição do material bibliográfico. São duas funções do mesmo processo que estão interligadas em razão de uma necessidade a ser atendida, considerando os recursos tecnológicos e as limitações financeiras. Em suma, não adianta o usuário possuir uma necessidade e a organização não possuir infraestrutura ou recursos financeiros para supri-la.

O profissional responsável pela aquisição vê-se então no seguinte dilema: possuir a propriedade física - impressa ou em CD-ROM, ou pagar pelo acesso on-line. Para as bibliotecas tradicionais, o acesso local garante um resultado tangível de um investimento realizado, já o acesso on-line representa um resultado intangível com um potencial de maior alcance.

A tecnologia da informação tem mudado radicalmente as formas de trabalho e o oferecimento de produtos. Nesse contexto, o serviço de aquisição deve considerar a infraestrutura disponível para acessar e disponibilizar informação antes de efetuar a compra de material bibliográfico.

Num ambiente onde o mercado de informação sofre mudanças radicais da noite para o dia, o profissional de aquisição precisa estar constantemente atualizado perante as novas tecnologias. Dentre as habilidades requeridas está a alfabetização digital, a habilidade de negociação e o conhecimento de línguas estrangeiras, 
pois o mercado fornecedor oferece versões modernas de novos produtos em idiomas variados.

Em qualquer das situações, a exigência é de um profissional com pensamento global, pois no atual contexto as informações são compartilhadas globalmente e "o fenômeno da globalização, como não poderia deixar de ser, tem trazido grande impacto na forma como as compras são efetuadas. Hoje, se fala em mercado global, e conseqüentemente, em compras globalizadas (global sourcing)" (MARTINS, 2000, p.70).

\section{O PROFISSIONAL DO SERVIÇO DE REFERÊNCIA}

No decorrer da história, pode-se observar através dos estudos da literatura da área de Biblioteconomia, a evolução do termo serviço de referência, seus aspectos conceituais, suas dimensões e peculiaridades.

O termo reference work é uma expressão inglesa emprestada ao Português e também utilizada por países de origem espanhola, vem do latim referentia, que serve para designar a ação de referir, contar, relatar. Portanto, o significado do verbo referir é de origem latina, cujo significado é responder, repetir, informar.

O termo serviço de referência é utilizado pelos bibliotecários para designar o serviço de informação ao usuário, serviço que aqui é compreendido em duas dimensões inseparáveis: a atitude do profissional de referência e o produto por ele oferecido ao usuário ou cliente da biblioteca ou centro de informação em que ambos estão inseridos.

A postura do profissional de referência pode ser dividida em duas partes: a primeira parte - que podemos generalizar extensiva a todos os profissionais que prestam qualquer tipo de serviço - engloba as atitudes pessoais tais como simpatia, criatividade, confiança, entusiasmo e outras; a segunda parte compreende o conhecimento específico da área, tais como a intimidade com as fontes de referência, vasta cultura geral, domínio das técnicas de buscas informatizadas, o entusiasmo pelas novas tecnologias, entre outras.

Para CHILD, citado por GROGAN, "Em sua respeitada opinião, 'as três primeiras (ualificações indispensáveis ao bibliotecário de referê cia são: $1^{\mathfrak{a}}$ ) experiência; $2^{a}$ ) experiência; $3^{a}$ ) experiêncie. '(1995, p.1).

É evidente que a experiência é uma importante qualificação necessária ao profissional que atua no serviço de referência, mas acreditamos que o aprendizado teórico pode compensar parte da distância entre um bibliotecário experiente e outro iniciante, nesse ponto GROGAN afirma:
"É claro que os livros não substituem a prática, mas podem preparar a mente para uma assimilação mais rápida da experiência, e desenvolver e ampliar a compreensão até mesmo das artes mais práticas, desde a construção de pontes até tocar violino" (1995, p.1).

Hoje, com as novas tecnologias da informação, as buscas em rede e a diversidade de bases de dados existentes, o profissional de referência iniciante, que souber formular estratégias de buscas adequadas possui tanto valor quanto um profissional com conhecimento adquirido ao longo do tempo.

Foi-se o tempo em que o bibliotecário conseguia armazenar na memória os assuntos e fontes existentes em uma biblioteca, hoje com a dinâmica de informações existentes no mundo, a prática da área mostra que novas informações são incorporadas diariamente aos sistemas de informação, seja através de ampliação do acervo, seja através do acesso a novas bases de dados interligadas via rede.

Outra observação, provavelmente percebida pelos leitores, é que ao nos referirmos ao bibliotecário de referência, algumas vezes utilizamos a palavra profissional de referência, isto vem da idéia e da observação na prática de que nem sempre o serviço de referência é executado apenas pelos bibliotecários, possuímos excelentes profissionais de outras áreas atuando na função, cumprindo seu papel a contento, tal é seu empenho e conhecimento profissional do dia-a-dia.

Em contraposição ao bibliotecário tradicional, que indicava onde a informação poderia ser encontrada, - inclusive, em alguns casos, abrindo o livro na página correta - hoje, o que se espera do profissional de referência é que ensine como formular métodos de busca eficazes aos usuários ou clientes do sistema de informação. A cada dia que passa as pessoas estão mais auto-suficientes, não possuindo dificuldades para fazer pesquisas com o auxílio do computador.

Adote-se aqui o conceito de MOLLER: "O serviço é um produto" (1997, p. 155). Na sociedade do conhecimento, o produto que se espera ser oferecido por um profissional de referência não é somente a informação em si, mas, sim, onde ela pode ser encontrada e de que forma ela pode ser recuperada.

É a geração do self service, que exige um profissional de referência capaz de perceber o comportamento de seu usuário ou cliente e ofereça um serviço adequado à sua forma de agir. 


\section{A RECUPERAÇÄO DA INFORMAÇÄO}

Neste final de século, as novas tecnologias permitiram armazenar uma quantidade quase ilimitada de informações, exigindo do bibliotecário de referência uma mudança radical nas formas de recuperação da mesma.

Além do antigo sistema de catálogos manuais, passaram-se a utilizar as buscas on-line, a exemplo da Internet, que apresenta um volume de informações quase que ilimitado, demandando maior tempo no refinamento da informação.

Existem, portanto, duas formas de pensar a recuperação da informação: interna - acervo da própria biblioteca - e externa - acesso a outras bibliotecas ou base de dados via on-line.

Apesar desse novo panorama apresentado pelas novas tecnologias de tratamento e recuperação da informação, as tradicionais " fichinhas" arquivadas por autor, título ou assunto ainda são práticas utilizadas em muitas bibliotecas que ainda não tiveram oportunidade de utilizar computadores, outras que estão em fase de transição, ou outras que, ainda, preferem manter as duas formas de recuperação de informação - catálogo manual e catálogo informatizado.

Segundo nossa interpretação, o paradigma atual adotado é: quem não tem um computador em sua biblioteca ou centro de informação está na Idade da Pedra. Com essa afirmação percebe-se a importância do uso do computador pelos profissionais que tratam do armazenamento e recuperação da informação. A razão é bastante simples, existe hoje no mundo uma inundação de informações que exige computadores para melhorar a eficácia da prestação de serviços, além disso, o barateamento cada vez maior na aquisição de novos softwares e hardwares não justifica o não uso do mesmo.

Outro fato em destaque é o intercâmbio entre bibliotecas, que, evidentemente, já podia ser feito via telefone ou fax, porém, por interligação via web tornouse mais eficaz.

Hoje, é possível acessar bases de dados de outras bibliotecas, sendo possível oferecer um serviço com maior qualidade aos usuários de sistemas de informação.

"As bases de dados são muitas vezes as mesmas, pelo menos superficialmente, o sistema de busca baseiase em comandos ou menus, ou uma mistura de ambos, as buscas por assuntos baseiam-se em vocabulário controlado ou palavras-chave, ou ambos, empregando se necessário lógica booleana, e o que aparece na tela pode ser impresso ou gravado em disco, conforme a preferência" (GROGAN,1995, p.131).
Os computadores estão mudando a vida das pessoas. Os profissionais do serviço de referência passam a ser gerenciadores de acesso à base de dados.

\section{A RELAÇÃO COM O USUÁRIO}

A primeira vez que se ouviu falar da relação usuário-bibliotecário registrada pela literatura data de 1876 na conferência histórica de bibliotecários, Samuel Swett Green, da Worcester Free Library apresentou sua preocupação em estabelecer comunicação pessoal (ROTHSTEIN, 1995).

Tal preocupação vem evoluindo ao longo do tempo até os dias de hoje, nos quais o usuário passa a ser visto como cliente.

Em contrapartida, o profissional de referência assemelha-se a um consultor, pois ele presta atividades de assessoria aos seus clientes, essa visão é ratificada principalmente nas bibliotecas de empresas, onde o bibliotecário é visto como agente de informações ou information brokers.

Visto como um professor, o profissional de referência deve explicar aos usuários a melhor forma de utilização dos recursos da biblioteca ou centro de informação, ensinando a formular estratégias de busca em catálogos e/ou bases de dados, podendo, ainda, orientar sobre métodos para elaboração de monografias ou teses.

E o que dizer do serviço de relações públicas da biblioteca? Será que o profissional do serviço de referência, através de uma postura ética e profissional, não estaria contribuindo para melhorar a imagem de seu ambiente de trabalho ao orientar usuários sobre normas, horário de funcionamento e serviços oferecidos?

E por que não encarar o bibliotecário de referência como um profissional de vendas, pois no seu contato com o usuário ele faz a ligação entre o produto (serviço) que se tem a oferecer e uma necessidade do usuário a ser satisfeita?

Em qualquer dos casos, é necessário tato na forma de conversar com os usuários e empatia para entender os seus problemas, só assim poderemos criar um clima de confiança na relação profissional do serviço de informação com seu cliente.

"O caráter intensamente pessoal do serviço de referência, que atende a uma necessidade tão fundamental quanto o anseio de conhecer, significa que seus princípios básicos pouco mudaram, se é que mudaram ao longo de quase um século, desde que foram estabelecidos" (GROGAN,1995, p. 3). 


\section{DESAFIOS PARA O GERENCIAMENTO EM BIBLIOTECAS OU CENTROS DE INFORMAÇÄO}

Vejamos esta breve introdução histórica:

"O desenvolvimento do sistema capitalista de produção, particulannente ao longo dos últimos 150 anos, ao colocar novas exigências educacionais, visando à produção e reprodução de mão-de-obra mais qualificada, acarretou uma grande ampliação das matrículas escolares e a elevação do nivel educacional das populações dos paises hoje ditos centrais ou hegemônicos. Na onda da valorização da educação como mecanismo de mobilidade entre as classes sociais, algumas instituições culturais, como as bibliotecas, particularmente as bibliotecas universitárias e públicas, adquiriram, a partir de meados do século 19, um grande impulso, passando a ser vistas como instrumentos auxiliares do processo de educação formal e um dos mais democráticos mecanismos de realização da chamada educação permanente.

Fenômeno semelhante se deu, já no século 20, com as bibliotecas especializadas de apoio à pesquisa científica e ao desenvolvimento tecnológico, processo que passou a ser, nas sociedades industrializadas, o principal motor de seu desenvolvimento econômico e social. Tornava-se evidente, não apenas para uma elite reduzida, mas para setores mais amplos da vida politica e social, que se estava lidando com um novo fator de produção, que era o conhecimento novo, ou, como se passou a dizer, a informação. Passa-se a falar da sociedade da informação, como antes se falara da sociedade da máquina a vapor, da sociedade do carvão ou da sociedade do aço.

A partir do fim da $2^{a}$ Guerra Mundial, começa a ocorrer um aumento vertiginoso da produção cientifica expressa na forma de artigos e livros cientificos. Falase da explosão da informação. E pouco tempo depois começam a ser feitas as primeiras experiências de aplicação do computador - a mais importante invenção do século, cuja matéria-prima a ser processada será exatamente a informação - visando a permitir a organização adequada do volume crescente de publicações científicas e técnicas" (LEMOS, 1998, p. 352-353).

Mais adiante, o autor complementa:

A grande mudança nesse setor se deu a partir do inicio da década de 1990, com a implementação da Internet, que possibilitou a interconexão de computadores de diferentes marcas e com diferentes sistemas operacionais, utilizando linhas telefônicas comuns combinadas com linhas de transmissão de dados de alta velocidade. (...) a Internet ensejou uma ampla difusão dos OPACS (online public access catalogs), que são exatamente isso: catálogos de bibliotecas disponiveis em linha e abertos à consulta remota por parte de qualquer interessado. Muitas bibliotecas que já haviam informatizados seus catálogos para acesso em redes locais tomaram-se assim, imediatamente disponiveis em escala mundial (LEMOS, 1998, p. 364-365).

Após esta rápida introdução histórica, que vem inclusive apontar diferenças entre as bibliotecas tradicionais e as bibliotecas atuais, podemos começar a pensar nos desafios relacionados ao gerenciamento da área.

Em primeiro lugar, destacamos o desafio de ordem estrutural, ou seja, é necessário analisar quais as características da biblioteca ou centro de informação em foco. É uma biblioteca pública ou privada? É de conhecimentos gerais ou é biblioteca especializada? Possui catálogo informatizado ou utiliza catálogo manual?

O primeiro desafio foi lançado, e corresponde à estrutura que se tem disponível. $\mathrm{Na}$ era do conhecimento, não podemos mais conceber uma biblioteca ou centro de informação que não possua computadores para tratamento e recuperação da informação via $\mathrm{CD}$ e on-line. Se isso não ocorre, já podemos apontar o início da atividade de gerenciamento, qual seja, adequar as condições estruturais da biblioteca ou centro de informação para que, mesmo em condições mínimas, atenda as exigências da sociedade do conhecimento.

$\mathrm{Na}$ era do conhecimento, as organizações serão flexíveis, com estruturas achatadas, trabalharão em equipe e por projetos, a exemplo da Microsoft, onde qualquer funcionário pode apresentar um projeto para o desenvolvimento de um novo produto.

Neste contexto estão inseridos as bibliotecas ou centros de informação que deverão, através do gerenciamento do seu capital humano, possuir características de organizações que aprendem.

Para gerenciar o capital intelectual é necessário: "(... ) desenvolver bases de dados de informação intelectual gerada e organizada pela própria instituição" (TARAPANOFF, 1997, p. 23).

Mas como funcionariam essas bases de dados na prática? É o segundo desafio do gerenciamento, que requer perspicácia para saber utilizar os conteúdos das bases de dados que compõem o capital humano da biblioteca ou centro de informação.

"A virada do milênio que coincide com a transformação da sociedade industrial em sociedade da informação, desencadeará uma verdadeira avalanche de mudanças e grandes desafios, a serem enfrentados pelos líderes e liderados da sociedade do terceiro milênio" (SILVA, 1998, p. 33). 


\section{A FUNÇÃO DO GERENTE/LÍDER}

Qualquer organização que fracasse ou que obtenha sucesso deve-o direta ou indiretamente à figura do gerente, pois este profissional é o responsável pelos resultados de sua equipe.

É importante aqui mencionar que o gerente tem sob suas mãos o poder de decidir, tanto sobre questões relacionadas à estrutura física, como também sobre o comportamento de sua equipe, deverá ele utilizar todos os recursos da organização da melhor forma possível.

Porém, o gerente é um ser humano, com origens e valores morais, que leva a certo comportamento de acordo com sua formação de caráter e também de acordo com as condições estruturais que ele possui. Dessa forma, existem gerentes: reativos, proativos, autocráticos, democráticos, liberais, entre outros. A formação acadêmica do gerente também influencia seu estilo de gestão.

Mas aqui cabe-nos perguntar quem são os gerentes responsáveis pelas bibliotecas ou centros de informações no Brasil? Qual a sua origem acadêmica?

Em pesquisa nacional realizada traçando o perfil do profissional de informação no Brasil, pudemos identificar:

"Dentre os que responderam à mostra nacional, (...) o grupo mais representativo foi o dos bibliotecários, (...) o que corresponde a $82,54 \%$ da amostra" (TARAPANOFF, 1997, p. 32).

Ora, se a maior parte dos profissionais de informação no Brasil é composta por bibliotecários, provavelmente os cargos de gerência são ocupados, na maioria por eles, nesse caso, é conveniente analisar o que se sabe sobre o currículo das escolas de Biblioteconomia no Brasil.

A análise dos dados mostrou uma postura não totalmente engajada, ou de alerta para todas as novas possibilidades, revelando um grande número de problemas, tanto da parte do profissional quanto da unidade informacional e, também, das escolas que preparam o profissional, os componentes do triângulo assumem uma postura bastante conservadora, comprometendo o desenvolvimento da área e a capacidade de adaptação do profissional e da unidade informacional, que, no momento, está muito aquém do necessário, mesmo numa fase de transição como a atual. Desnecessário alertar que as mudanças hoje ocorrem com muito maior rapidez que há dez anos atrás (TARAPANOFF, 1997, p. 56).

Face aos resultados obtidos na pesquisa de Tarapanoff, conclui-se que é necessário mudar o paradigma atual dos profissionais da informação no
Brasil, o que só se consegue através de mudança na base, ou seja, repensando o currículo das escolas de Biblioteconomia, ao agregar disciplinas de cunho gerencial. Acreditamos que problemas estruturais da unidade de informação podem ser resolvidos através de definição de estratégias em busca de recursos, de alçada da gerência da unidade.

Não são de se estranhar os resultados da pesquisa, pois o Brasil apresenta problemas semelhantes em diversas áreas, por exemplo, as escolas de Administração têm se preocupado muito com o perfil do profissional que se está colocando no mercado. Estariam as escolas de Administração formando gerentes ou líderes? Qual a diferença entre os dois?

Gerente é palavra em desuso, principalmente, quando aliada à postura de controle, supervisão, cobrança de resultados, mas com méritos apenas para a figura do gerente. A visão tradicional que se tem do gerente é que a equipe trabalha e ele leva os méritos. Isso deve-se ao modelo adotado no século passado, onde o gerente planejava e o funcionário executava, o chamado modelo taylorista.

O líder, por sua vez, deve possuir vasta cultura geral, facilidade de trabalhar em equipe, ser auto-confiante, comprometer-se com o que faz, liderar pelo exemplo e pelo carisma. Mas, se sua postura for controladora, ameaçadora, que não divide informações, que não possui habilidade no trato com sua equipe, tem-se aí o gerente do século passado, querendo obter sucesso através de sua equipe.

Os chefes não mais serão donos exclusivos de seus recursos humanos ou materiais. Estes recursos serão negociados e compartilhados com outros chefes $e$ departamentos, alocados em diferentes projetos ou grupos de trabalho. Há uma tendência a prevalecer o tipo de organização mais conhecida como matricial, onde os recursos são compartilhados com vários outros departamentos e gerentes. Por outro lado, a tendéncia é acabar com o organograma e criar organizações gerenciadas por processos horizontais" (SILVA, 1998, p. 63).

O gerenciamento dos recursos, e principalmente do capital humano em bibliotecas ou centros de informação de sucesso, exige por parte dos responsáveis em cargos de direção, postura de líder - o líder sábio - é esse o perfil profissional do terceiro milênio, um líder com valores éticos, que seja respeitado e que saiba respeitar a equipe, liderando mais pelo exemplo do que pela ameaça de punição.

Para VANTI: "é fundamental educar dando o exemplo, através de um real comprometimento com as ações do coletivo, ganhando assim credibilidade e ressaltar, constantemente, a importância da contribuição dos funcionários" (1999, p. 237). 
O principal recurso a ser utilizado pelo líder em bibliotecas ou centros de informação, é, sem dúvida, o capital humano, ou seja, o conhecimento de seus colaboradores. A ferramenta a ser utilizada é uma base de dados com esse conhecimento, que poderá alocar cada funcionário em cada projeto de trabalho, de acordo com o que ele sabe.

Parece que os novos modelos gerenciais apontam para uma postura holística do líder, que deve conhecer as habilidades de sua equipe.

Além disso, a nova forma de gestão deve ser descentralizada, o novo papel do gerente passa a ser o de facilitador do processo, conseguindo resultados com as pessoas e não através das pessoas.

O trabalho em equipe é outro paradigma gerencial do terceiro milênio, o novo modelo gerencial é coordenar equipes interdisciplinares, no caso de bibliotecas ou centros de informação, em função das novas tecnologias, teremos uma equipe composta por programadores, analistas de sistemas, administradores, língüistas, bibliotecários, professores, pesquisadores... o que demanda um líder capaz de conseguir resultados com um grupo de profissionais advindos de diversas áreas.

O compartilhamento de informações é outro destaque do novo modelo gerencial, o líder deve ter capacidade de comunicação, - formal ou informal - e não ter medo de perder poder ao estar compartilhando informações.

\section{CONSIDERAÇÕES FINAIS}

Pudemos perceber que as bibliotecas ou centros de informação encontram-se em uma fase de transição e, por conseguinte, não se sabe ainda como será o futuro, mas algumas certezas já começam a tomar forma, entre elas estão a necessidade de mudar e a necessidade de um melhor aproveitamento do principal recurso do momento - o conhecimento.

Os gestores de bibliotecas ou centros de informação encontram-se numa grande encruzilhada, sem saber que caminho tomar, pois as organizações estão descobrindo que as pessoas são insubstituíveis em função do conhecimento tácito que possuem, este de difícil transferência a outras pessoas, pois como podemos transferir a experiência profissional adquirida por um colaborador ao longo dos anos num determinado processo de trabalho, principalmente na área de informação?

Desafio maior ainda é fazer com que tal colaborador use tal conhecimento em busca de melhorias do processo.
É preciso que a mudança comece pelo modelo gerencial adotado pelos atuais gestores. A gestão do órgão deve oferecer oportunidades para o funcionário colocar suas idéias em prática, participar de cursos de atualização profissional, e dessa forma desenvolver-se profissionalmente.

Evidente que não existem "receitas mágicas para o sucesso", pois sabemos que o funcionamento das bibliotecas ou centros de informações podem apresentar características culturais capazes de impossibilitar até mesmo a adequação da estrutura que permita desenvolver um ambiente criativo, sem contar o aspecto técnico voltado para normas e regras ditadas pelos sistemas de catalogação da área biblioteconômica.

Porém, acreditamos que todo início de processo de mudança pode, a princípio assustar, mas jamais devemos descartar a possibilidade de tornar as bibliotecas ou centros de informações organizações que aprendem, pois tudo inicia-se na mudança do modelo mental de seus gestores.

O principal aspecto desse novo modelo mental deve iniciar em um contrato de parceria entre gestor e colaborador, visando atingir objetivos que sejam bons para ambas as partes, porém tal relação de confiança somente será consolidada através do comportamento de ambos ao longo do tempo.

O operário do conhecimento visa o reconhecimento profissional, e quer participação em projetos importantes dentro das organizações, dessa forma, quanto mais habilidades ele possuir, maior a possibilidade de participar de diversos projetos.

Em contrapartida, o gestor quer resultados atingidos, em conseqüência, precisa conhecer as habilidades de seus colaboradores. Para tanto, pode-se criar uma base de dados com o cadastro de habilidades dos colaboradores, tal base de dados deve ser constantemente atualizada, e a cada novo projeto pode-se estudar quem poderá participar, prevendo-se inclusive formas de reconhecimento aos colaboradores.

Nossas considerações tentaram responder algumas perguntas, tais como: Qual a melhor forma de utilizar o capital humano para o desenvolvimento das bibliotecas ou centros de informações? Como conseguir o comprometimento dos nossos colaboradores para com os objetivos organizacionais? Que estratégias devemos utilizar para desenvolver o capital humano dos funcionários em ambientes de bibliotecas ou centros de informações?

Queremos deixar claro aos leitores que as idéias aqui abordadas não devem ser interpretadas como algo pronto ou acabado, pois sabemos que é impossível 
encontrar soluções fáceis para problemas complexos, pois que: complexo é o ser humano, mais complexo ainda é querer fazê-lo comportar-se de acordo com os interesses da organização.

Com certeza, qualquer estudo teórico pode nos levar à falsa impressão de que as aplicações práticas são simples, mas sabemos que cada organização tem sua história, que algumas organizações são mais flexíveis, outras são mais engessadas, que existem pessoas com objetivos nem sempre convergentes dentro das organizações, que existem lutas pelo poder que dificultam o trabalho de equipe, que alguns líderes vêem mais longe do que outros, isso tudo nos leva a crer que o ambiente em que está situado o centro de informação ou biblioteca é que determinará qual distância ele deve percorrer até tornar-se uma learning organization.

\section{REFERÊNCIAS BIBLIOGRÁFICAS}

GROGAN, Denis. A prática do serviço de referência/Denis Grogan; tradução de Antonio Agenor Brinquet de Lemos. Brasília, DF: Briquet de Lemos/Livros. 1995.

GUIMARÃES, José Augusto. Moderno profissional da informação : elementos para sua formação e atuação no Mercosul com vistas ao terceiro milênio. Encuentro de Directores, 3 Y Docentes de las Escuelas de Bibliotecologia del Mercosur, 2 (Santiago (Chile) : 1998). Anais... Santiago (Chile) : Universidad Tecnológica Metropolitana,1998.

LANCASTER, F. W. Ameaça ou oportunidade? O futuro dos serviços de biblioteca à luz das inovações tecnológicas. R. Esc. Biblioteconomia UFMG, Belo Horizonte, v. 23, n. 1, p. 7-27, Jan.-Jun, 1994.

LEMOS, Antonio Agenor Briquet de. Bibliotecas. In: CAMPELLO, Bernadete Santos, CALDEIRA, Paulo da Terra, MACEDO, Vera Amália Amarante (Coord.). Formas e expressões do Conhecimento. Belo Horizonte: Escola de Biblioteconomia da UFMG,1998. p. 347-366.

LUCAS, Clarinda Rodrigues. A Organização do conhecimento e tecnologias da informação. Transinformação, Campinas, v. 8, n. 3, p.59-65, set./dez.1996.
MARCHIORI, Patrícia Zeni. Que profissional queremos formar para o século XXI: graduação. Inf. \& Inf., Londrina, v.1, n. 1, p. 27-34, jan./jun.1996.

MARENGO, Lucia. A Sociedade da informação e o mercado de trabalho. Transinformação, Campinas, v. 8, n.1, p.112-143, jan./abr.1996.

MARTINS, Petrônio Garcia. Administração de materiais e recursos patrimoniais. São Paulo : Saraiva, 2000.

MASON, R. O. What is an information professional. Journal of Eduaction for Library and Information Science. 31 (2): p.122-138, fall 1990.

MOLLER, Claus. O lado humano da qualidade. São Paulo: Pioneira,1997 (tradução)

PONJUÁN DANTE, Glória. Papel de las escuelas de Biblioteconomia en la transformación del profesional modemo de la información. In: ENCONTRO NA-CIONAL DE ENSINO DE BIBLIOTECONOMIA E CIÉNCIA DA INFORMAÇÃO, 4. São Paulo, 21-23 ago./1995. Conferência de Encerramento.

ROTHSTEIN, S.1995. The developement of reference services through academic traditions, public library practice and special librarianship. (ACRL monographs, 14) Cap. 2 - The genesis of reference seivice: 1875-1895.

SENGE, Peter M. A Quinta disciplina. (tradução) OP TRADUÇÕES, São Paulo: Editora Best Seller. 1998.

SILVA, Lenilson Naveira e. Líder sábio: Novo perfil de liderança do Terceiro Milênio. Rio de Janeiro: Record,1998. $336 \mathrm{p}$.

STEWART, T. A. Capital intelectual : a nova vantagem competitiva das empresas. 5. Ed. Rio de Janeiro : Campus, 1998. 239p.

TARAPANOFF, Kira. Perfil do profissional da informação no Brasil: Diagnóstico de necessidades de treinamento $e$ educação continuada. Brasília: IELDF Editora, 1997. $136 \mathrm{p}$.

VANTI, Nadia. Ambiente de qualidade em uma Biblioteca Universitária: aplicação do $5 \mathrm{~S}$ e de um estilo participativo de administração. Revista Perspectivas em Ciência da Informação, Belo Horizonte. v.4, n 2, p. 231-242, jul./ dez. 1999.

WORMELL, Irene. Habilidade de gerenciamento e de empreendimento na profissão de bibliotecário e cientista da informação. Inf. \& Inf., Londrina, v. 4, n.1, p. 07-16, jan. jun. 1999. 